\title{
A case of reversible Mobitz type II atrioventricular block after the use of injectable antipsychotics
}

\author{
Hisao Naono ${ }^{1}$, Ryuichiro Takeda ${ }^{2}$, Hiroyuki Masuyama ${ }^{3}$, Jiro Kawano ${ }^{3}$, Keiko \\ Naono-Nagatomo ${ }^{4}$, and Yasushi Ishida ${ }^{2}$ \\ ${ }^{1}$ Doshinkai Koga General Hospital \\ ${ }^{2}$ University of Miyazaki \\ ${ }^{3}$ Miyazaki Prefectural Miyazaki Hospital \\ ${ }^{4}$ Miyazaki Prefectural Mental Health Welfare Center
}

November 21, 2021

\begin{abstract}
Although Mobitz type II atrioventricular block is an arrhythmia based on a permanent organic disorder of the His-Purkinje system, reversible factors should be considered. Here, we report the association between a rare reversible Mobitz type II atrioventricular block and antipsychotic medication in a 75-year-old patient with schizophrenia.
\end{abstract}

\section{Hosted file}

Manuscript.doc available at https://authorea.com/users/447320/articles/546325-a-caseof-reversible-mobitz-type-ii-atrioventricular-block-after-the-use-of-injectableantipsychotics

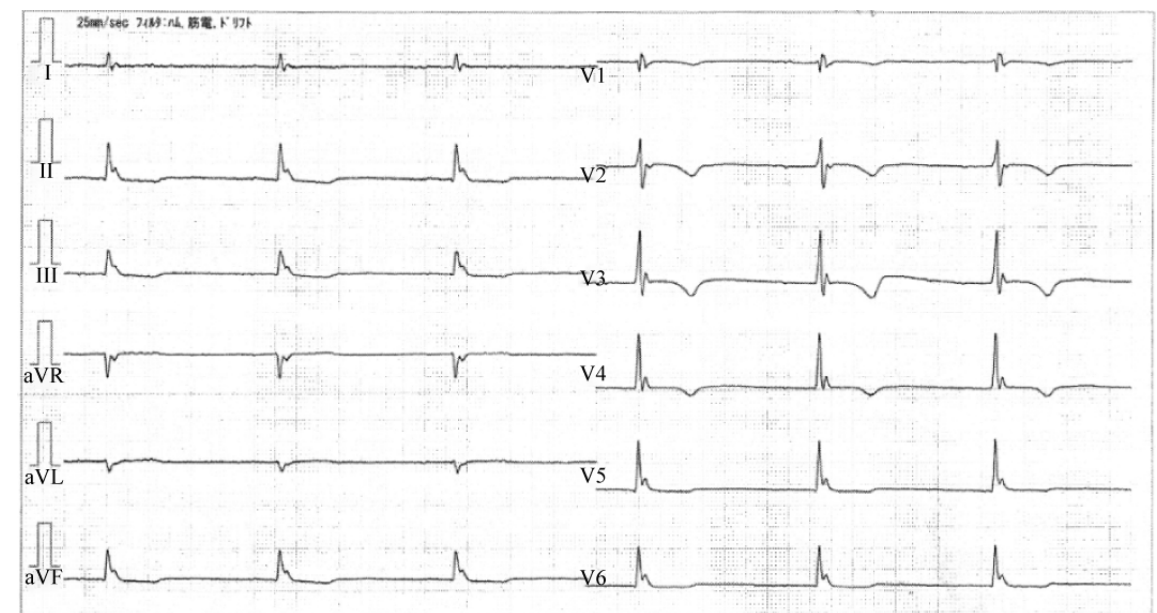


(a)

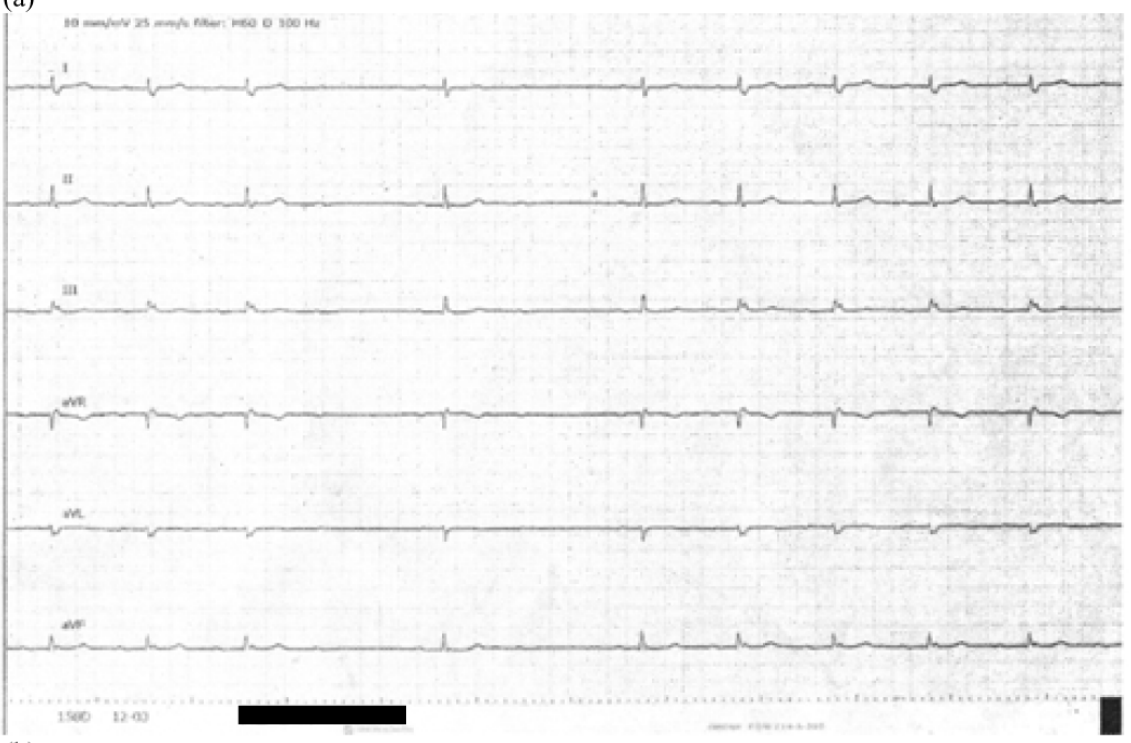

(b)

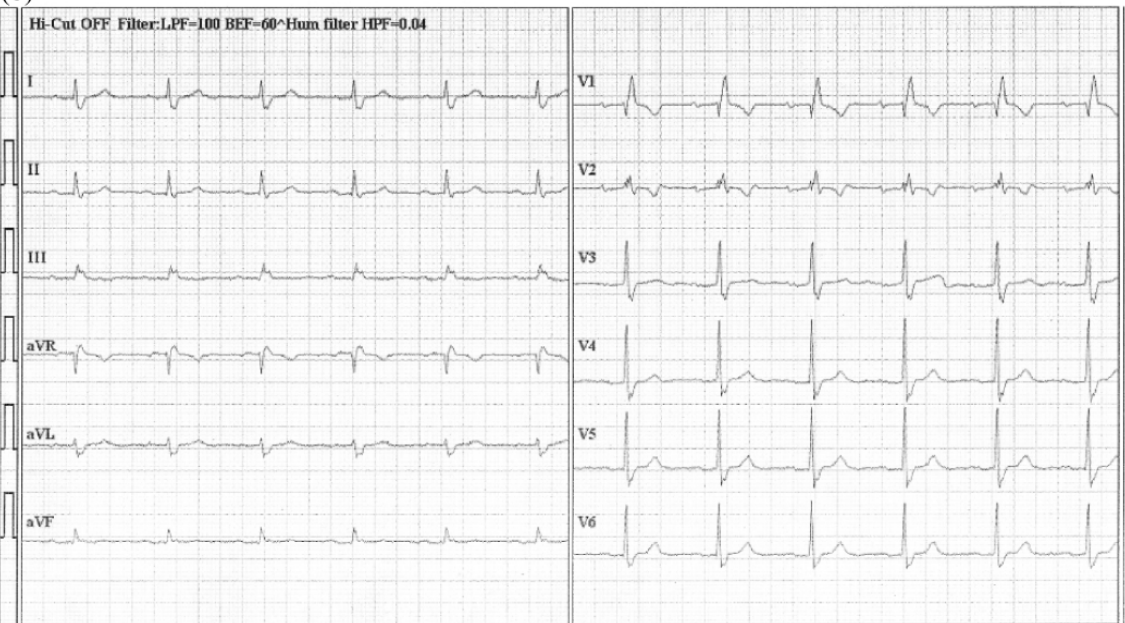

